\title{
Immunohistochemical Properties of Ocular Adenomas, Adenocarcinomas, and Medulloepitheliomas
}

\author{
A Senior Honors Thesis: \\ Presented in partial fulfillment of the requirements for graduation with distinction in Zoology in \\ the undergraduate college of Arts and Sciences of The Ohio State University. \\ By: \\ Emily Klosterman \\ The Ohio State University \\ June 2005 \\ Project Advisors: \\ Carmen M.H. Colitz, DVM, PhD, DACVO, Assistant Professor Ophthalmology \\ David Culver, PhD, Professor EEOB
}




\begin{abstract}
:
Ocular medulloepitheliomas, adenomas and adenocarcinomas share a common phenotype and originate from the cells of the ciliary epithelium. This can make it very difficult to differentiate between these tumors histopathologically. Therefore, this study focused on identifying a combination of immunological markers that might be used in the diagnosis of these tumors. These markers included AE1/AE3, CK7, CK20, and telomerase reverse transcriptase (TERT).

Routine immunohistochemical staining was performed on twenty-one whole globes diagnosed with one of these tumors. The tumors that immunostained for TERT showed increasing immunoreactivity as the tumor types increased in aggressiveness. None of the tumor types were immunopositive for CK7. CK20 immunostaining was found in the adenomas but not in the adenocarcinomas or medulloepitheiomas. AE1/AE3 expression was present more consistently in the adenocarcinomas and less frequently in the adenomas. There was no AE1/AE3 expression in the medulloepitheliomas confirming their mesenchymal origin. Furthermore, CK20 and TERT show inverse expression patterns, i.e., TERT increases in expression and CK20 decreases in expression with increasing aggressiveness. These results may be important diagnostic and prognostic indicators for these tumors. (195 words)
\end{abstract}

\title{
Key Words:
}

Immunohistochemistry, medulloepithelioma, adenocarcinoma, adenoma, telomerase, telomerase reverse transcriptase (TERT), CK7, CK20, AE1/AE3 


\section{Introduction:}

Medulloepithelioma is an extremely rare congenital, unilateral ocular tumor that arises mainly from the undifferentiated nonpigmented epithelium of the ciliary body (optic cup). ${ }^{1,15,20}$ The tumor originates from portions of the embryonic medullary epithelium of the forebrain and optic vesicles (neuroectoderm); as such, these tumors have the ability to differentiate into various cell types. ${ }^{15}$ There are two classifications of this tumor: teratoid and non-teratoid medulloepitheliomas. Teratoid medulloepitheliomas contain heteroplastic tissues not normally seen in the mammalian eye, such as cartilage, muscle fibers, and neuronal tissue. Nonteratoid and teratoid medulloepitheliomas are unlike retinoblastoma in their pluripotential properties. ${ }^{46}$ Medulloepitheliomas arise most frequently in young children but they have also been described in other species, including dogs, cats, horses, cockatiels, a goldfish, and a llama.,15,5,10,17,22$25,37,42,45$

It is often difficult to differentiate medulloepitheliomas from other tumors that arise from the ciliary epithelium, i.e. adenomas and adenocarcinomas. Therefore, this study focused on characterizing these tumors using a variety of antibodies. These endeavors are especially important for neoplasms of veterinary species where information is more limited. This study also sought to investigate the expression of TERT, the catalytic subunit of telomerase. Telomerase is a ribonucleoprotein complex that is present in the majority of tumors to allow unlimited replicative abilities by maintaining the telomeres. Telomerase activity has been used in tumors of humans and dogs to predict prognosis and aggressiveness of the tumors. $3,14,16,38,43$ TERT was used in this study as an indirect marker of telomerase activity. ${ }^{16}$ 


\section{Materials and Methods:}

- Tissue Preparation

Twenty seven samples were obtained from the Ophthalmic Pathology Service from The School of Veterinary Medicine, University of Wisconsin. There were fourteen adenoma samples, categorized as either non-invasive $(n=7)$ or invasive $(n=7)$. Seven samples were classified as adenocarcinomas, and six specimens were medulloepitheliomas. All samples were canine ocular globes (Table 1), which were fixed in 10\% buffered neutral formalin, paraffin embedded, and evaluated histologically by Dr. Dubielzig, our collaborative veterinary ophthalmic pathologist. Sections were cut at $5 \mu \mathrm{m}$ onto charged slides (Probe-On Plus, Fisher Scientific, Pittsburg, PA) for immunohistochemical staining.

- Antibodies

Immunohistochemical staining was performed using antibodies against telomerase reverse transcriptase (TERT, Santa Cruz, 1:350), CK7 (CK 7, Super Sensitive Ready-to-Use Antibody, BioGenex, San Ramon, CA), CK20 (CK 20, Super Sensitive Ready-to-Use Antibody, BioGenex, San Ramon, CA), CKAE1 and CKAE3 (DAKO Corp., Carpinteria, CA, 1:50). DAKO Antibody Diluent with Background Reducing Components (DAKO Corp., Carpinteria, CA) was used for antibodies requiring dilution.

TERT (Santa Cruz Biotechnology, Inc.,) is an affinity-purified goat-anti-rabbit polyclonal antibody raised against a peptide mapping at the carboxy terminus of telomerase reverse transcriptase of human origin. TERT was used at a 1:350 dilution. CK20 (Super Sensitive Ready-to-Use Antibody, BioGenex, San Ramon, CA) is a mouse monoclonal antibody diluted in phosphate buffered saline, $\mathrm{pH} 7.6$ containing 1\% BSA and $0.09 \%$ sodium azide. CK7 (Super Sensitive Ready-to-Use Antibody, BioGenex, San Ramon, CA) is a mouse monoclonal antibody 
from ascites and diluted in phosphate-buffered saline, $\mathrm{pH} 7.6$ containing 1\% BSA and $0.09 \%$ sodium azide. Anti-AE1/AE3 is a cocktail of two monoclonal antibodies for cytokeratins; and it is used to identify cells of simple and stratified epithelial origin. ${ }^{41}$ Staining for this antibody was performed by The Ohio State University Immunohistochemical Staining Laboratory.

- Immunohistochemical staining

The avidin-biotin peroxidase complex (ABC) method was used with all antibodies. ${ }^{8}$ Samples were deparaffinized in xylene and rehydrated in decreasing concentrations of alcohols followed by washing in $1 \mathrm{X}$ phosphate-buffered saline (PBS). Slides were incubated for 10 minutes at $37^{\circ} \mathrm{C}$ with DAKO Ready-to-Use Peroxidase Blocking Reagent (DAKO Corp., Carpinteria, CA) to block endogenous peroxidase activity. Slides were then incubated with DAKO Ready-to-Use Protein Block Serum (Dako Corp., Carpinteria, CA) for 10 minutes at $37^{\circ} \mathrm{C}$ to block nonspecific protein binding. Samples were incubated with the appropriate primary antibody overnight at $4^{\circ} \mathrm{C}$, washed, then incubated in secondary antibody (mouse or rabbit Biogenex Super Sensitive Link, Biotinylated Immunoglobulins, Biogenex, San Ramon, CA) for 45 minutes at $37^{\circ} \mathrm{C}$. Slides were labeled with Biogenex Super Sensitive Label, Peroxidase-Conjugated Streptavidin for 30 minutes at $37^{\circ} \mathrm{C}$. Immunostaining was then visualized with either 3,3马diaminobenzidine tetrahydrochloride (DAB, DAKO Corp., Carpinteria, CA), prepared according to instructions for 3 minutes at room temperature in the dark or Vector NovaRED (Vector Laboratories, Burlingame, CA) for 5 minutes at room temperature. Following washes, slides were counterstained with hematoxylin for 3 minutes at room temperature, dehydrated and permanently mounted. For negative controls, primary antibodies were omitted and samples were incubated in DAKO Antibody Diluent with Background Reducing Components (DAKO Corp., Carpinteria, CA). 
One additional step, antigen retrieval, was included following the rehydration which unmasked hidden epitopes when staining with TERT, CK20 and CK7. TERT was treated with DAKO Target Retrieval Solution (DAKO Corp., Carpinteria, CA) for 20 minutes in a steam bath then 20 minutes at room temperature. CK20 was pretreated with Protease (Invitrogen, Carlsbad, CA) for 10 minutes at room temperature. CK7 was pretreated with Pepsin (Biogenex, San Ramon, CA) for 5 minutes at $37^{\circ} \mathrm{C}$.

A pathologist blinded to the details of the study (Dr. Donna Kusewitt) interpreted the immunohistochemistry results. Results were rated as positive (the majority of tumor cells were positive), negative (all of the tumor cells were negative), or $+/$ - which indicated that some tumors cells were positive while others were negative. These ratings were assigned a number: majority of cell were positive (2), few positive cells (1), or negative (0); and statistical analysis was performed using a one way ANOVA with Tukey's test of comparable means (Prism 4 software).

\section{Results:}

Positive telomerase staining was seen as red since NovaRED was used as the chromogen. CK20, CK7 and AE1/AE3 had brown positive staining because DAB was used as the chromogen. The immunohistochemical staining results for each tumor sample are listed in Table 2.

Non-invasive adenomas were found to be significantly immunoreactive $(\mathrm{p}<0.001)$ for CK20 when compared to invasive adenomas, adenocarcinomas, and medulloepitheliomas (Figures 1-5 B). Non-invasive adenomas had significantly less immunostaining for TERT than invasive adenomas, adenocarcinomas, and medulloepitheliomas. There was no significant difference in immunostaining for AE1/AE3 in adenocarcinomas when compared to non-invasive 
and invasive adenomas, but medulloepitheliomas were immunonegative for AE1/AE3 (Figures 1-4 C and 5C). All tumors were negative for CK7 (Figures 1-4 D).

The invasive adenomas expressed significantly less CK20 than the noninvasive adenomas. They expressed significantly more TERT than the noninvasive adenomas. There was no significant difference in expression of AE1/AE3 between invasive adenomas, noninvasive adenomas and adenocarcinomas. None of the invasive adenomas expressed CK7 (Figure 2).

Adenocarcinomas did not express CK7 or CK20, but TERT and AE1/AE2 were expressed in this tumor type (Figure 3). Medulloepitheliomas did not express CK20, CK7 or AE1/AE3, but this tumor type expressed TERT (Figure 4).

Immunoreactivity for TERT was seen in all four tumor-types with increasing immunoreactivity as the tumors increased in aggressiveness (Figures 1-5 A). The non-invasive adenomas showed less immunoreactivity with the anti-TERT antibody than the other tumors $($ mean $=0.4286)$. The invasive adenomas $($ mean $=1.822)$, adenocarcinomas $($ mean=2.000), and medulloepitheliomas (mean=2.000) were all strongly immunopositive with anti-TERT antibody. The invasive adenomas, adenocarcinomas, and medulloepitheliomas had significantly more TERT immunoreactivity than the non-invasive adenomas $(\mathrm{p}<0.001)$.

CK20 was expressed with the non-invasive adenomas and some of the invasive adenomas (Figures 1 and 2 B). CK20 was not expressed in the adenocarcinomas or medulloepitheliomas (Figures 3 and 4 B). CK7 was not reactive with any of the tumor-types (Figures 1-4 D). AE1/AE3 were expressed infrequently in the adenomas and more consistently in the adenocarcinomas (Figures 1-3 C). AE1 and AE3 were not present in any medulloepitheliomas (Figure 4). 


\section{- Statistical Significance}

The data for tumor immunoreactivity for TERT showed a significant difference between the non-invasive adenomas and the other three tumor types, the invasive adenomas, adenocarcinomas and medulloepitheliomas (Figure $5 \mathrm{~A}$ and Table 3). The p-values for these comparisons were all less than 0.05. The invasive adenomas, adenocarcinomas, and medulloepitheliomas expressed more TERT than the non-invasive adenomas.

CK20 immunoreactivity was significantly higher in the non-invasive adenomas when compared to the invasive adenomas, adenocarcinomas, and medulloepitheliomas (Figure 5 B and Table 3). The p-values for these comparisons were all less than 0.05 . All tumors received a score of 0 for immunoreactivity with CK7, therefore, statistical analysis was not performed on these.

AE1/AE3 immunoreactivity was significantly higher in the adenocarcinomas than the adenomas (Figure $5 \mathrm{C}$ and Table 3). None of the medulloepitheliomas were positive for AE1/AE3.

\section{Discussion:}

Medulloepitheliomas are usually locally aggressive and may infiltrate the area around the lens. ${ }^{20}$ The tumors can be malignant or benign, and histologically, demonstrate poorly differentiated neuroectodermal tissue that may resemble embryonic retina. ${ }^{46}$ Large HomerWright and Flexner-Wintersteiner rosettes can also be observed. ${ }^{15,20,26}$ Numerous studies have characterized these tumors using immunohistochemical staining. ${ }^{5,18,20}$ The neuroepithelial cells are positive for neuron-specific enolase, vimentin, S-100 protein, synaptophysin, and glial fibrillary acidic protein (GFAP). ${ }^{20,26,46}$ The neuroblastic cells are usually positive for neuron- 
specific enolase and synaptophysin. ${ }^{46}$ Medulloepitheliomas originate from the ciliary epithelium as do adenomas and adenocarcinomas making their diagnostic differentiation difficult. Though metastasis is atypical for all three tumor types, it is still important to properly diagnose them especially if they are identified early and excised without enucleation of the globe.

Adenocarcinomas occur more frequently in adult humans and show a wide range of severity, from differentiated malignant neoplasms to poorly differentiated pleomorphic tumors. Adenocarcinomas histopathologically show increased necrosis and mitosis, as well as pleomorphism when compared to adenomas which only show moderate pleomorphism and few mitoses; adenomas are usually benign. ${ }^{26}$ Adenomas express vimentin, S-100 protein, and lowmolecular weight cytokeratins. ${ }^{46}$ The tumors can show a variety of histological patterning including tubular, solid, and tubular/solid combination patterns and the cells are often heavily pigmented and vacuolated. Adenocarcinomas also show these patterning types and they have been shown to express vimentin, epithelial basement membrane antigen, and S-100 protein. ${ }^{46}$

Telomerase is a ribonucleoprotein complex that maintains telomeres, the ends of chromosomes, in most neoplastic cells, germline cells, and some stem cells. ${ }^{19}$ Expression of telomerase activity allows cellular immortality by preventing the shortening of telomeres. ${ }^{4,36}$ The functional telomerase complex is comprised of two main components, the catalytic subunit, TERT, and the RNA subunit, TR. TR is expressed in most cells including those that lack telomerase activity ${ }^{12}$ but TERT is the limiting factor in which expression correlates with telomerase activity. ${ }^{9,2,31,44}$ TERT also has anti-apoptotic functions independent of TR. ${ }^{13,27,28,47}$ The combination of TERT's anti-apoptotic functions and its function as the catalytic subunit of the telomerase holoenzyme complex are synergistic in their effects on the immortality of neoplastic and other telomerase-positive cells. Since telomerase activity can only be evaluated in 
fresh tissues by the telomeric repeat amplification protocol, ${ }^{19}$ an indirect method of evaluating telomerase activity was used, that is, immunohistochemical staining for the TERT protein. ${ }^{21}$ Numerous tumors, including neuroblastomas, malignant brain tumors, and colon, breast and ovarian carcinomas, as well as others $6,7,16,32,33,38,39$, have a strong correlation between TERT mRNA and/or protein expression and telomerase activity. In addition, expression of TERT by immunohistochemical evaluation has correlated strongly with aggressiveness and metastatic potential. $^{16,32}$ The tumors evaluated in this study are not typically highly metastatic but they can be locally aggressive; therefore, TERT and the other markers were used in an effort to create a set of prognostic and diagnostic criteria for their behavior.

TERT expression was seen in three of the four tumor-types with increasing immunoreactivity as the tumor types increased in aggressiveness. The non-invasive adenomas showed little to no expression of TERT supporting their benign nature. This was statistically significant when compared to the other tumors evaluated $(\mathrm{p}<0.0001)$; almost all of the invasive adenomas (85.7\%) expressed TERT and all of the adenocarcinomas and medulloepitheliomas had strong immunoreactivity for TERT, indicating that their behavior was more aggressive when compared to the non-invasive adenomas. These findings support the premise that telomerase activity is increased in tumor cells to allow uncontrolled proliferation and more aggresive behavior.

Cytokeratins are important components of the cytoskeleton found in epithelial cells and tumors of epithelial origin. ${ }^{11,26}$ There are twenty different cytokeratins and their expression is tissue-specific, thus cytokeratin typing can be important in analyzing tumors and deducing their origin. ${ }^{11,26} \mathrm{CK} 7$ is an intermediate filament protein that has been found in the glandular epithelium of many organs including lung, cervix, ovary, and breast, as well as urinary bladder 
transitional epithelium, bile ducts, collecting ducts of the kidney, and mesothelium. ${ }^{34} \mathrm{CK} 7$ is absent in the gastrointestinal epithelium, hepatocytes, proximal and distal tubules of the kidney, prostate, thymus, Merkel cells, and myoepithelium. ${ }^{34}$ The protein is also absent in adenocarcinomas of the gastrointestinal epithelium ${ }^{34,35}$ as well as all of the tumors evaluated in this study.

CK20 is an intermediate filament protein usually expressed in adenocarcinomas originating from the epithelium of the intestine, colon, ovary, urothelium, and Merkel cells. ${ }^{29,30}$ CK20 has also been found in breast, lung, and endometrial carcinomas, but not in the nonneoplastic epithelial cells of these organs. ${ }^{11}$ This study found that CK20 was expressed in both non-invasive and invasive adenomas but not in adenocarcinomas. This lends support to the idea of the protein being expressed in well-differentiated cells but not in cells of the same type as they become more neoplastic and aggressive. Since medulloepitheliomas are of mesenchymal origin, they were not expected to and did not express CK20.

Anti-cytokeratins AE1 and AE3 recognize the keratin subfamily; they can be used to differentiate between epithelial and non-epithelial neoplasms. AE1 specifically recognizes the keratins in the acidic subfamily and AE3 recognizes the keratins in the basic subfamily. AE3 has been found in both nonpigmented ciliary epithelial tumor cells and non-neoplastic cells, whereas AE1 was only expressed in tumor cells. ${ }^{40}$ This study found the adenocarcinomas to have the highest expression of AE1/AE3 with less expression in the adenomas. This suggests that AE1/AE3 expression increases as the tumors become more aggressive. Since medulloepitheliomas are of mesenchymal origin, they were not expected to and did not express AE1/AE3. 
In this study, cytokeratins $\mathrm{AE} 1$ and $\mathrm{AE} 3$ were expressed more consistently in the adenocarcinomas and variably in the non-invasive and invasive adenomas. This is in contrast to CK20, which was positive in most of the non-invasive adenomas but decreased in expression as tumors increased in aggressiveness. The non-invasive adenomas were the only tumor type found to be immunoreactive with CK20 and showed little or no reactivity for TERT. This would further support TERT and telomerase activity's role in neoplastic progression. CK20 expression decreased as the ciliary body tumors became more aggressive. AE1 and AE3 were not present in any medulloepitheliomas confirming that they are not originating from ectodermal tissue; previous studies have shown them to express vimentin, confirming their mesenchymal origin. ${ }^{5,15}$ The AE1/AE3 results confirm that, unlike medulloepitheliomas, adenomas and adenocarcinomas are of ectodermal origin. CK7 was not reactive with any of the tumor-types.

AE1/AE3 keratins and cytokeratins 7 and 20 have been used to characterize human pleomorphic adenocarcinomas of the ciliary epithelium. AE1/AE3 immunostaining was found in most adenocarcinomas, similar to our study; CK7 immunostaining was found in almost half of the tumors; and CK20 was not expressed in any tumor. ${ }^{26}$ This is opposite to the findings of this study and may be species specific or perhaps characteristic to the pleomorphic nature of the human tumor.

The results of this study demonstrate some distinct immunostaining patterns for the tumors evaluated (Table 3). The results add new information to the current available knowledge regarding these tumor types. Of special interest is the inverse expression of telomerase and CK20. These results may be important in predicting the behavior of these tumors and may be useful for the diagnosis and differentiation of adenomas, adenocarcinomas, and medulloepitheliomas. 


\section{Acknowledgements:}

The authors would like to sincerely thank Heather Chandler and staff of the Laboratory of

Molecular and Comparative Ophthalmology for the guidance, assistance and support that was provided. 


\section{References:}

1 al-Torbak A, Abboud EB, al-Sharif A, el-Okda MO: Medulloepithelioma of the ciliary body. Indian J Ophthalmol 50: 138-140, 2002

2 Beattie TL, Zhou W, Robinson MO, Harrington L: Reconstitution of human telomerase activity in vitro. Current Biology 8: 177-180, 1998

3 Biller BJ, Kitchell BE, Cadile CD: Evaluation of an assay for detecting telomerase activity in neoplastic tissues of dogs. Am J Vet Res 59: 1526-1529, 1998

4 Blasco MA, Gasser,S.M., Lingner,J.: Telomeres and telomerase. Genes and Development 13: 2353-2359, 1999

5 Bras ID, Metzler AG, Kusewitt DF, Colitz CMH, Wilkie DA: Immunohistochemical characterization of a malignant intraocular teratoid medulloepithelioma in a cockatiel. Vet Ophthalmol 8: 59-65, 2005

6 Braunstein I, Cohen-Barak O, Shachaf C, al e: Human telomerase reverse transcriptase promoter regulation in normal and malignant human ovarian epithelial cells. Cancer Res 61: 5529-5536, 2001

7 Cabuy E, de Ridder L: Telomerase activity and expression of telomerase reverse transcriptase correlated with cell proliferation in meningiomas and malignant brain tumors in vivo. Virchows Arch 439: 176-184, 2001

8 Colitz CMH, Malarkey DE, Dykstra MJ, McGahan MC, Davidson MG: Histologic and immunohistochemical characterization of lens capsular plaques in dogs with cataracts. Am J Vet Res 61: 139-143, 2000

9 Dhaene K, Van Marck E, Parwaresch R: Telomeres, telomerase and cancer: an up-date. Virchows Arch 437: 1-16, 2000

10 Eagle RC, Font RL, Swercsek TW: Malignant medulloepithelioma of the optic nerve in a horse. Vet Pathol 15: 488-494, 1978

11 Espinosa de los Monteros A, Fernandez A, Millan MY, Rodriguez F, Herraez P, Martin de las Mulas J: Coordinate expression of CK7 and 20 in feline and canine carcinomas. Vet Pathol 36: 179-190, 1999

12 Feng J, Funk WD, Whang S-S, Weinrich SL, Avilion AA, Chiu C-P, Adams RR, Chang E, Allsopp RC, Yu J, Le S, West MD, Harley CB, Andrews WH, Greider CW, Villeponteau B: The RNA Component of Human Telomerase. Science 269: 1236-1241, 1995

$13 \mathrm{Fu} \mathrm{W}$, Killen M, Pandita TK, Mattson MP: The catalytic subunit of telomerase is expressed in developing brain neurons and serves a cell survival-promoting function. J Mol Neurosci 14: 3-15, 2000

14 Funakoshi Y, Nakayama,H., Uetsuka,K., Nishimura,R., Sasaki,N., Doi,K.: Cellular proliferation and telomerase activity in canine mammary gland tumors. Vet Pathol 37: 177-183, 2000

15 Hendrix DVH, Bochsler PN, Saladina B, Cawrse MA, Thomas J: Malignant teratoid medulloepithelioma in a llama. Vet Pathol 37: 680-683, 2000

16 Ickowski KA, Pantazis CG, McGregor DH, Wu Y, Tawfik OW: Telomerase reverse transcriptase subunit immunoreactivity. A marker for high-grade prostate carcinoma. Cancer 95: 2487-2493, 2002 
17 Jelinek F, Mirejovsky P, Voskova D, Hron P: Medulloepithelioma in a cat. Cesko-slovenska patologie 32: 75-77, 1996

18 Khoddami M, Becker LE: Immunohistochemistry of medulloepithelioma and neural tube. Pediatric Pathology \& Laboratory Medicine 17: 913-925, 1997

19 Kim NW, Piatyszek MA, Prowse PR, Harley CB, West MD, Ho PLC, Coviello GM, Wright WE, Weinrich SL, Shay JW: Specific association of human telomerase activity with immortal cells and cancer. Science 266: 2011-2014, 1994

20 Kivela T, Tarkkanen A: Recurrent medulloepithelioma of the ciliary body. Ophthalmology 95: $1565-1575,1988$

21 Kyo S, Masutomi K, Maida Y, Kanaya T, Tanaka M, Takarada M, Sugawara I, Murakami S, Taira T, Inoue M: Significance of immunological detection of human telomerase reverse transcriptase. Am J Pathol 163: 859-867, 2003

22 LaBowit SE, Katz,H.R., Hirschbein,M.J., Oswald,M.R., Snyder,L.S., Schwartz,K.S., Herling,I.E.: Topical $0.3 \%$ ciprofloxacin vs topical $0.3 \%$ ofloxacin in early treatment of pseudomonas aeruginosa keratitis in a rabbit model. Ann Ophthalmol 33: 48-52, 2001

23 Lahav M, Albert DM: Medulloepithelioma of the ciliary body in the goldfish(Carassius auratus). Vet Pathol 15: 208-212, 1978

24 Lahav M, Albert DM, Kircher CH, Percy DH: Malignant teratoid medulloepithelioma in a dog. Vet Pathol 13: 11-16, 1976

25 Langloss JM, Zimmerman LE, Krehbiel JD: Malignant intraocular teratoid medulloepithelioma in three dogs. Veterinary Pathology 13: 343-352, 1976

26 Laver NM, Hidayat AA, Croxatto JO: Pleomorphic adenomas of the ciliary epithelium: Immunohistochemical and ultrastructural features of 12 cases. Ophthalmology 106: 103, 1999

27 Mattson MP, Fu W, Zhang P: Telomerase, DNA Damage and Apoptosis. In: Telomerase, Aging and Disease, eds. Mattson MPPandita TK, pp. 131-150. Elsevier Science, Amsterdam, 2001

28 Mattson MP, Klapper,W.: Emerging roles for telomerase in neuronal development and apoptosis. Journal of Neuroscience Research 63: 1-9, 2001

29 Moll R, Lowe A, Laufer J, Franke WW: CK20 in human carcinomas. A new histodiagnostic marker detected by monoclonal antibodies. Am J Pathol 140: 427-447, 1992

30 Moll R, Schiller DL, Franke WW: Identification of protein IT of the intestinal cytoskeleton as a novel type I CKwith unusual properties and expression patterns. J Cell Biol 111: 567-580, 1990

31 Nakayama J-i, Tahara H, Tahara E, Saito M, Ito K, Nakamura H, Nakanishi T, Tahara E, Ide T, Ishikawa F: Telomerase activation by hTRT in human normal fibroblasts and hepatocellular carcinomas. Nature Genetics 18: 65-68, 1998

32 Poremba C, Heine B, Diallo R, Heinecke A, Wai D, Schaefer KL, Braun Y, Schuck A, Lanvers C, Bankfalvi A, Kneif S, Torhorst J, Zuber M, Kochli OR, Mross F, Dieterich H, Sauter G, Stein H, Fogt F, Boecker W: Telomerase as a prognostic marker in breast cancer: high-throughput tissue microarray analysis of hTERT and hTR. J Pathol 198: 181-189, 2002

33 Poremba C, Scheel,C., Hero,B., Christiansen,H., Schaefer,K.L., Nakayama,J.I., Berthold,F., Juergens,H., Boecker,W., Dockhorn-Dworniczak,B.: Telomerase activity and telomerase subunits gene expression patterns in neuroblastoma: a molecular and 
immunohistochemical study establishing prognostic tools for fresh-frozen and paraffinembedded tissues. Journal of Clinical Oncology 18: 2582-2592, 2000

34 Ramaekers F, Huysmans A, Schaart G, Moesker O, Vooijs P: Tissue distribution of keratin 7 as monitored by a monoclonal antibody. Exp Cell Res 170: 235-249, 1987

35 Ramaekers F, van Niekerk C, Poels L, Schaafsma E, Huijsmans A, Robben H, Schaart G, Vooijs P: Use of monoclonal antibodies to keratin 7 in the differential diagnosis of adenocarcinomas. Am J Pathol 136: 641-655, 1999

36 Rhyu MS: Telomeres, Telomerase and Immortality. J Natl Cancer Inst 87: 884-894, 1995

37 Schmidt RE, Becker LL, McElroy JM: Malignant teratoid medulloepithelioma in two cockatiels. J Am Vet Med Assoc 189: 1105-1106, 1976

38 Schneider-Stock R, Boltze C, Jager V, Epplen J, Landt O, Peters B, Rys J, Roessner A: Elevated telomerase activity, c-MYC, and hTERT mRNA expression: association with tumour progression in malignant lipomatous tumors. J Pathol 199: 517-525, 2003

39 Tahara H, Yasui W, Tahara E, al e: Immuno-histochemical detection of human telomerase catalytic component, hTERT, in human colorectal tumor and non-tumor tissue sections. Oncogene 18: 1561-1567, 1999

40 Terasaki H, Nagasaka T, Arai M, Harada T, Miyake Y: Adenocarcinoma of the nonpigmented ciliary epithelium: report of two cases with immunohistochemical findings. Graefes Arch Clin Exp Ophthalmol 239: 876-881, 2001

41 Tseng SCG, Jarvinen MJ, Nelson WG, Huang JW, Woodcock-Mitchell J, sun TTI: Correlation of specific keratins with different types of epithelial differentiation: Monoclonal antibody studies. Cell 30: 361, 1982

42 Ueda Y, Senba H, Nishimura T, Usui T, Tanaka K, Inagaki S: Ocular medulloepithelioma in a thoroughbred. Equine Veterinary Journal 25: 558-561, 1993

43 Wang Z, Ramin SA, Tsai C, Lui P, Ruckle HC, Beltz RE, Sands JF, Slattery CW: Evaluation of PCR-ELISA for determination of telomerase activity in prostate needle biopsy and prostatic fluid specimens. Urologic Oncology 7: 199-205, 2002

44 Weinrich SL, Pruzan,R., Ma,L., Ouellette,M., Tesmer,V.M., Holt,S.E., Bodnar,A.G., Lichsteiner,S., Kim,N.W., Trager,J.B., Taylor,R.D., Carlos,R., Andrews,W.H., Wright,W.E., Shay,J.W., Harley,C.B., Morin,G.B.: Reconstitution of human telomerase with the template RNA component hTR and the catalytic protein subunit hTRT. Nature Genetics 17: 498-502, 1997

45 Wilcock B, Williams MM: Malignant intraocular medulloepithelioma in a dog. Journal of the American Animal Hospital Association 16: 617-619, 1980

46 Yanoff M, Fine BS: Ocular Melanocytic Tumors. In: Ocular Pathology, 5 ed., pp. 639-699. Mosby, Philadelphia, 2002

47 Zagorski Z: Histopathological studies of human lenses. Lens Eye Toxic Research 8: 311-318, 1991 


\section{Tables:}

\section{Table 1:}

\section{Adenoma (Non-Inv)}

1

2

3

4

5

6

7
Slide ID

01RD287

01RD325

01RD597

01RD829

00RD895

00RD978

01RD1158
Signalment

FS, 9 yr, Lab Ret

FE, 6 yr, Greyhound

FE, 7 yr, Lab Ret

FS, 7 yr, Lab Ret

MN, 9 yr, Mix Breed

MN, 10 yr, Lab Ret

MN, 7 yr, ShepherdX
Diagnosis

non-pigmented, iridociliary adenoma

non-pigmented, iridociliary adenoma

partially pigmented, iridociliary adenoma non-pigmented, iridociliary adenoma partially pigmented, iridociliary adenoma non-pigmented, iridociliary adenoma non-pigmented, iridociliary adenoma

Adenoma (Invasive)

8

9

10

11

12

13

14

Adenocarcinomas

15

16

17

18

19

20

21
01RD084 MN, 5.2 yr, Aust Cattle Dg 94RD104 12 yr, Brittany Spaniel 98RD142

01RD324

00RD586

99RD648

00RD1100
FE, 8 yr, Shih Tzu

FS, 6 yr, Cocker/Terrier

FS, 6 yr, Boston Terrier

FS, 1 yr, German Shp

FS, 11 yr, Yorkshire Ter iridociliary adenoma non-pigmented, ciliary body tumor non-pigmented, ciliary body adenoma non-pigmented, iridociliary adenoma non-pigmented, iridociliary adenoma partially pigmented, iridociliary adenoma non-pigmented, iridociliary adenoma

Medulloepithelioma

$\begin{array}{llc}22 & \text { 92RD060 } & \text { ML, 6 yr, Lab Ret } \\ 23 & \text { 97RD114 } & \text { FE, 1 yr, Malamute } \\ 24 & \text { 02RD332 } & \text { unknown } \\ 25 & 96 R D 537 & \text { FE, 10 mo, Beagle } \\ 26 & \text { 97RD614 } & \text { FS, 4 yr, Lab Ret } \\ 27 & \text { 00RD1057 MN, 12 yr, Cocker Spaniel }\end{array}$

iridociliary adenocarcinoma iridociliary adenocarcinoma iridociliary adenocarcinoma iridociliary adenocarcinoma iridociliary adenocarcinoma iridociliary adenocarcinoma adenocarcinoma

00RD1279

FS, 6 yr, ShepherdX

MN, 9 yr, Poodle

MN, 8 yr, Lab Ret

, 10 yr, Golden Ret

MN, 12 yr, Mix Breed

$13 \mathrm{yr}$, ShepherdX 


\section{Table 2:}

\begin{tabular}{|c|c|c|c|c|c|}
\hline & Slide ID & & Antibodie & & \\
\hline Adenoma (Non-Invasive) & & TERT $(1: 350)$ & CK \#20 & $\mathrm{CK} \# 7$ & AE1:AE3 \\
\hline 1 & 01RD287 & 0 & 0 & 0 & 1 \\
\hline 2 & $01 \mathrm{RD} 325$ & 0 & 2 & 0 & 0 \\
\hline 3 & 01RD597 & 1 & 2 & 0 & 1 \\
\hline 4 & 01RD829 & 0 & 2 & 0 & 0 \\
\hline 5 & 00RD895 & 1 & 2 & 0 & 1 \\
\hline 6 & 00RD978 & 0 & 2 & 0 & 1 \\
\hline 7 & 01RD1158 & 1 & 0 & 0 & 1 \\
\hline
\end{tabular}

Adenoma (Invasive)

$\begin{array}{cccccc}8 & 01 \text { RD084 } & 1 & 2 & 0 & 0 \\ 9 & 94 R D 104 & 0 & 0 & 0 & 1 \\ 10 & 98 R D 142 & 2 & 0 & 0 & 1 \\ 11 & 01 \text { RD324 } & 2 & 2 & 0 & 1 \\ 12 & \text { 00RD586 } & 2 & 0 & 0 & 0 \\ 13 & 99 R D 648 & 2 & 0 & 0 & 1 \\ 14 & \text { 00RD1100 } & 2 & 0 & 0 & 0\end{array}$

Adenocarcinomas

$\begin{array}{lccccc}15 & \text { 01RD089 } & 2 & 0 & 0 & 2 \\ 16 & \text { 00RD0305 } & 2 & 0 & 0 & 2 \\ 17 & \text { 00RD0394 } & 2 & 0 & 0 & 0 \\ 18 & \text { 00RD0510 } & 2 & 0 & 0 & 2 \\ 19 & \text { 00RD1209 } & 2 & 0 & 0 & 2 \\ 20 & \text { 00RD1277 } & 2 & 0 & 0 & 2 \\ 21 & \text { 00RD1279 } & 2 & 0 & 0 & 1\end{array}$

Medulloepithelioma

22
23
24
25
26
27

$\begin{array}{ccccc}\text { 92RD060 } & 2 & 0 & 0 & 0 \\ \text { 97RD114 } & 2 & 0 & 0 & 0 \\ \text { 02RD332 } & 1 & 0 & 0 & 0 \\ \text { 96RD537 } & 2 & 0 & 0 & 0 \\ \text { 97RD614 } & 1 & 0 & 0 & 2 \\ \text { 00RD1057 } & 2 & 0 & 0 & 0\end{array}$




\section{Table 3:}

\begin{tabular}{l|c|c|c|c|}
\multicolumn{1}{c}{ Tumor Type } & TERT & CK 20 & CK 7 & \multicolumn{1}{c|}{ AE1/AE3 } \\
\hline $\begin{array}{l}\text { Adenoma (Non- } \\
\text { Invasive) }\end{array}$ & 0.4286 & 2.000 & 0.000 & 1.429 \\
\cline { 2 - 5 } $\begin{array}{l}\text { Adenoma (Invasive) } \\
\text { Adenocarcinoma }\end{array}$ & 1.833 & 0.5714 & 0.000 & 1.143 \\
\cline { 2 - 5 } Medulloepithelioma & 2.000 & 0.000 & 0.000 & 1.571 \\
\cline { 2 - 5 } & 2.000 & 0.000 & 0.000 & 0.000 \\
& & & & \\
\end{tabular}

Data presented is the mean of the immunostaining rating. 


\section{Figures:}

Figure 1: Non-invasive adenoma immunostained for (A) telomerase, (B) for CK20 (CK 20), (C) AE 1/AE 3, and (D) CK7 (CK 7). Chromogen is NovaRed for telomerase antibody and DAB for CK20, CK7, and AE1/AE3, all are counterstained with hematoxylin, magnification is 40X.
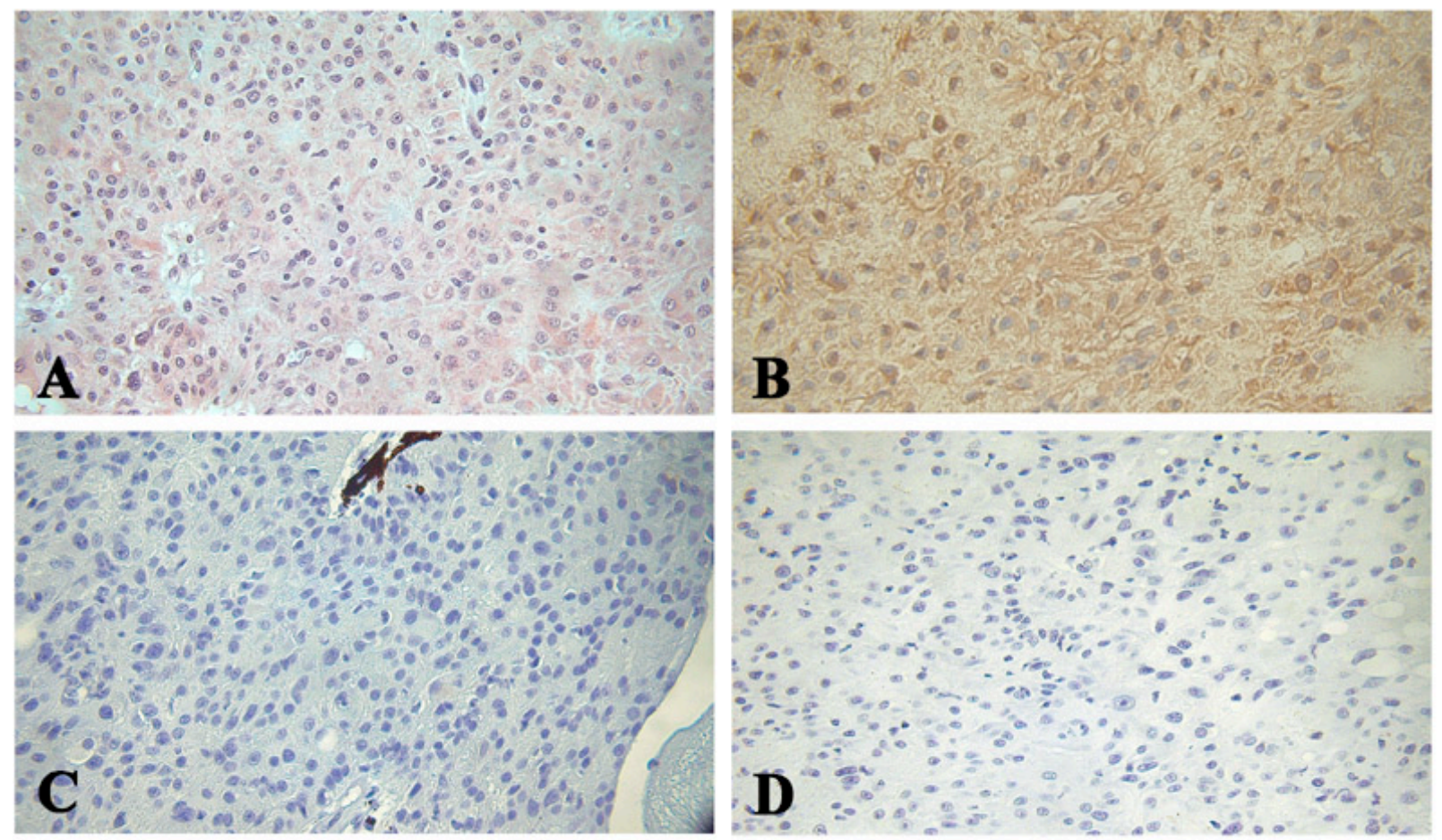
Figure 2: Invasive adenoma immunohistochemically stained for (A) telomerase, (B) CK20 (CK 20), (C) AE 1/AE 3, and (D) CK7 (CK 7). Chromogen is NovaRed for telomerase antibody and $\mathrm{DAB}$ for $\mathrm{CK} 20, \mathrm{CK} 7$, and AE1/AE3, all are counterstained with hematoxylin, magnification is $40 \mathrm{X}$.
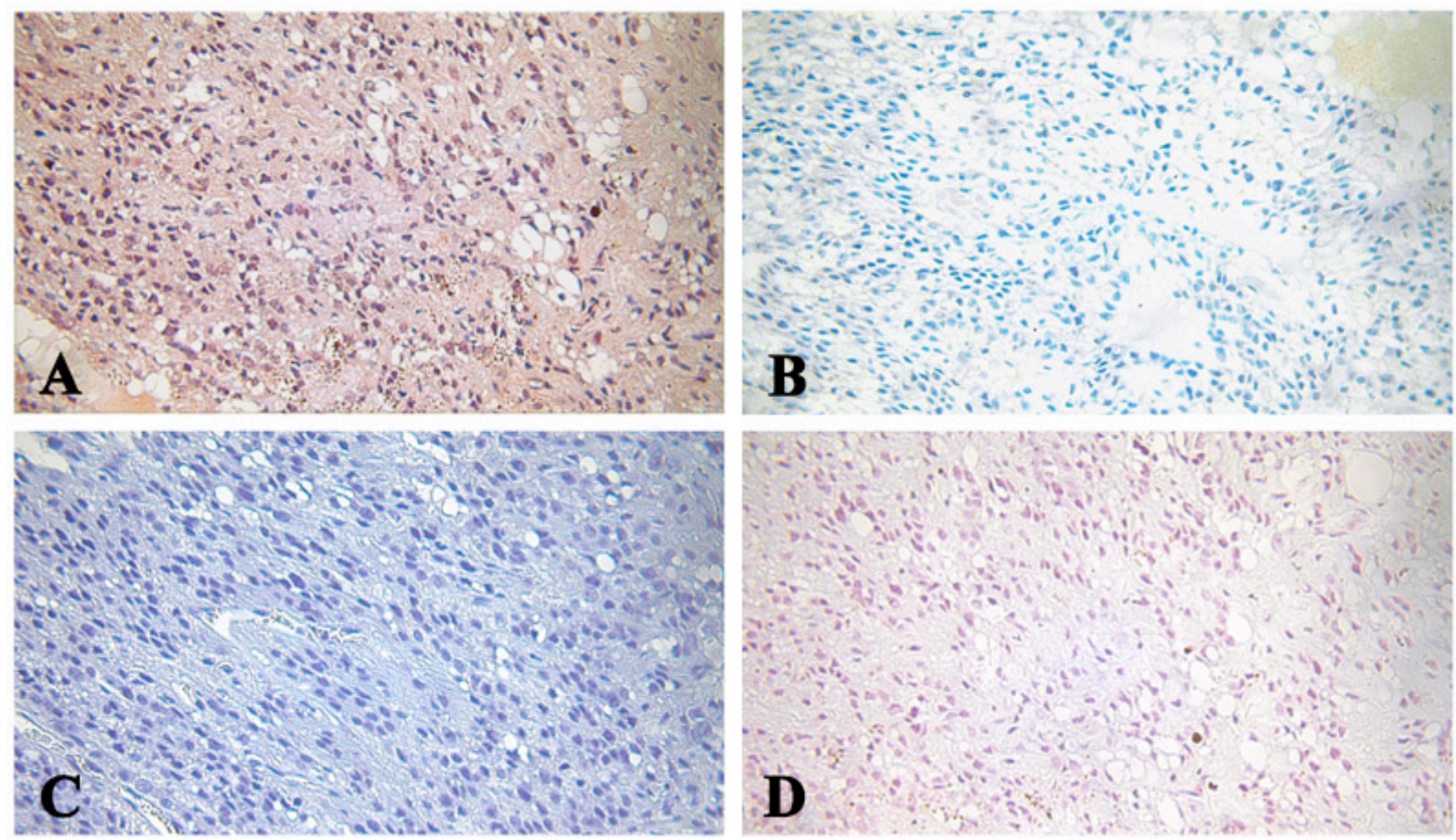
Figure 3: Adenocarcinoma immunohistochemically stained for (A) telomerase, (B) CK20 (CK 20), (C) AE 1/AE 3, and (D) CK7 (CK 7). Chromogen is NovaRed for telomerase antibody and $\mathrm{DAB}$ for CK20, CK7, and AE1/AE3, all are counterstained with hematoxylin, magnification is 40X.
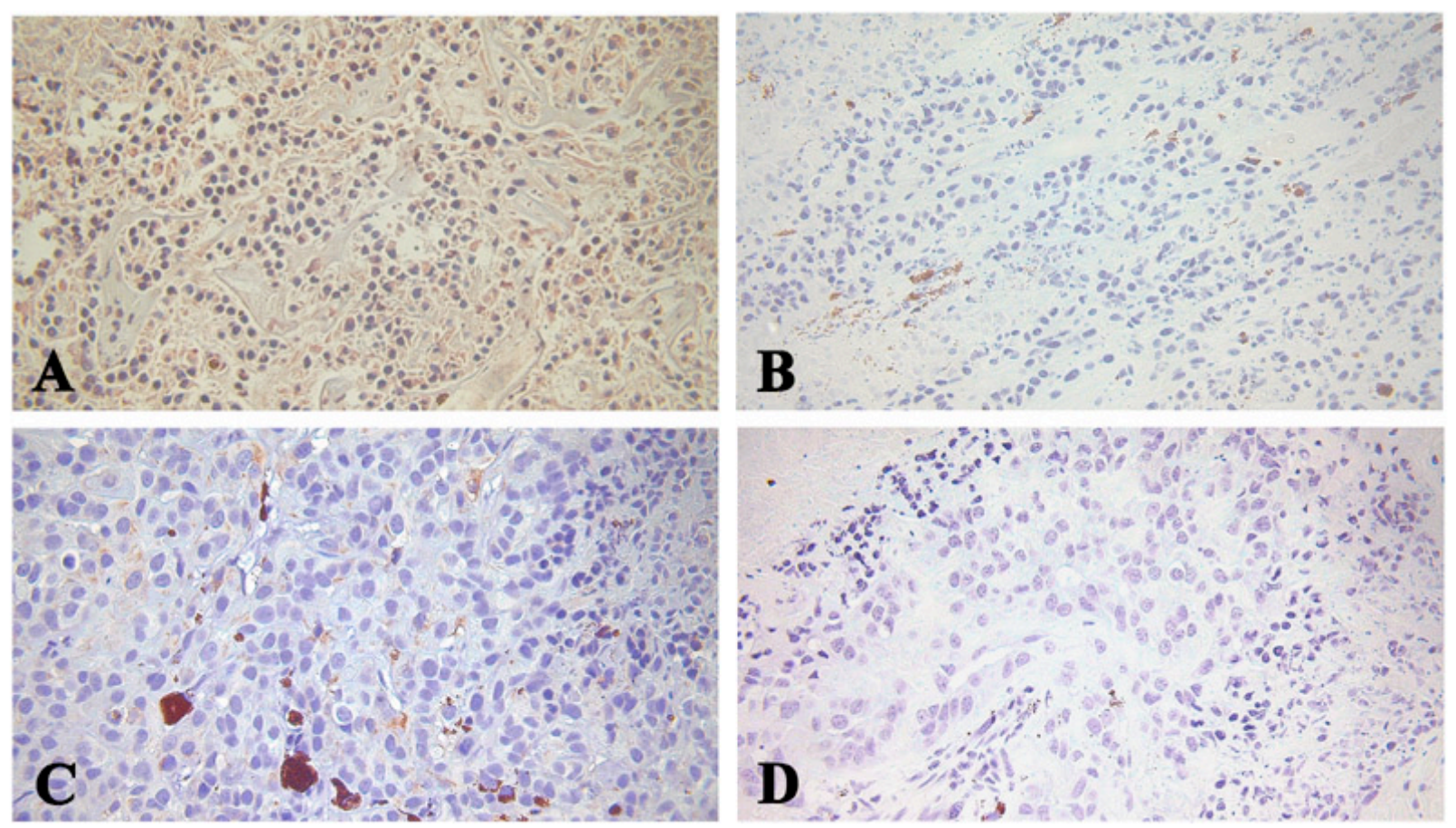
Figure 4: Medulloepithelioma immunohistochemically stained for (A) telomerase, (B) AE 1/AE 3 , and (C) AE 1/AE 3 and (D) CK7 (CK 7). Chromogen is NovaRed for telomerase antibody and $\mathrm{DAB}$ for $\mathrm{CK} 20, \mathrm{CK} 7$, and AE1/AE3, all are counterstained with hematoxylin, magnification is $40 \mathrm{X}$.
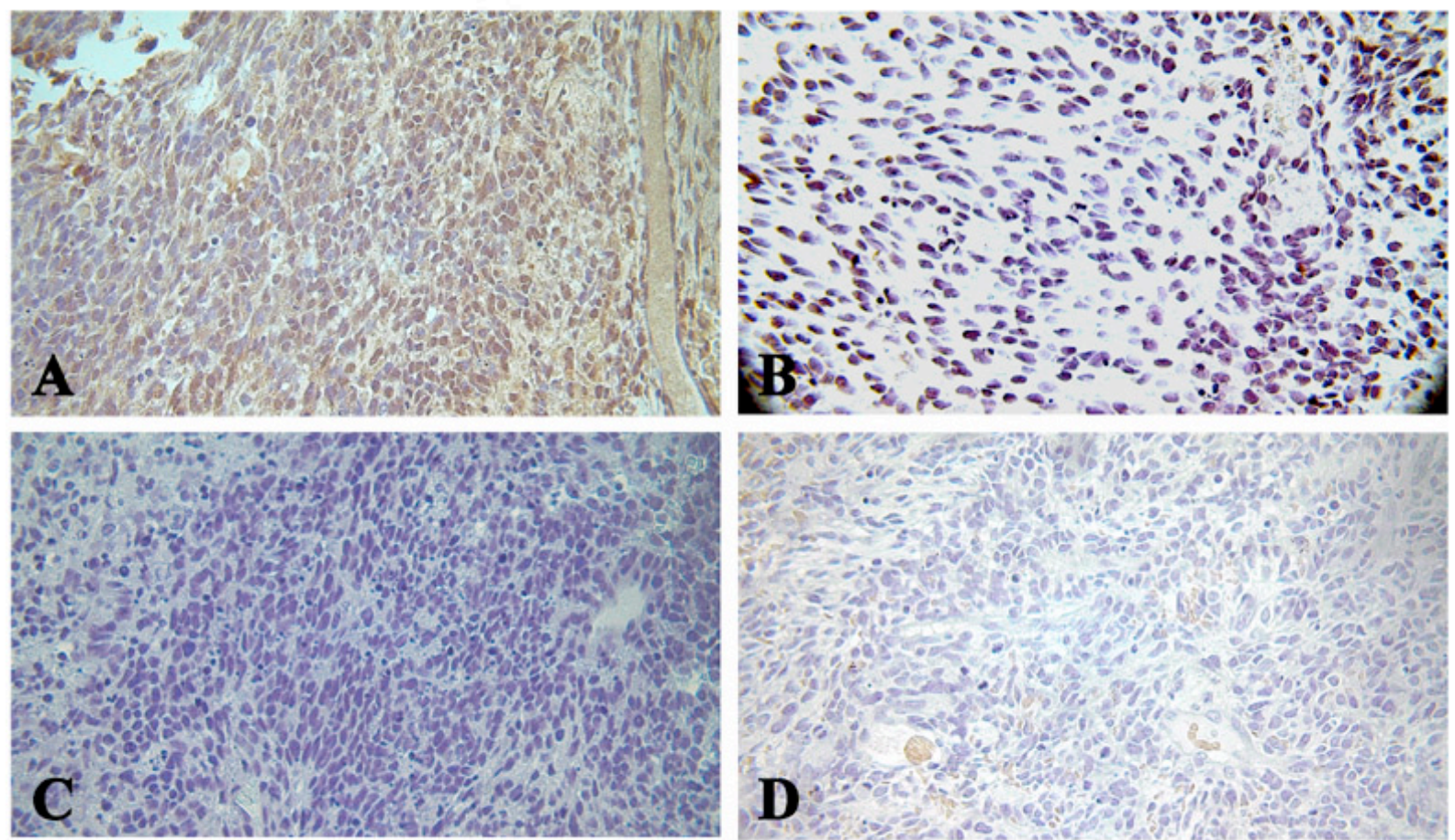
Figure 5: Bar graphs of immunohistochemical staining score averages for tumors stained with (A) TERT, (B) CK20, and (C) AE1/AE3.

$\mathbf{A}$
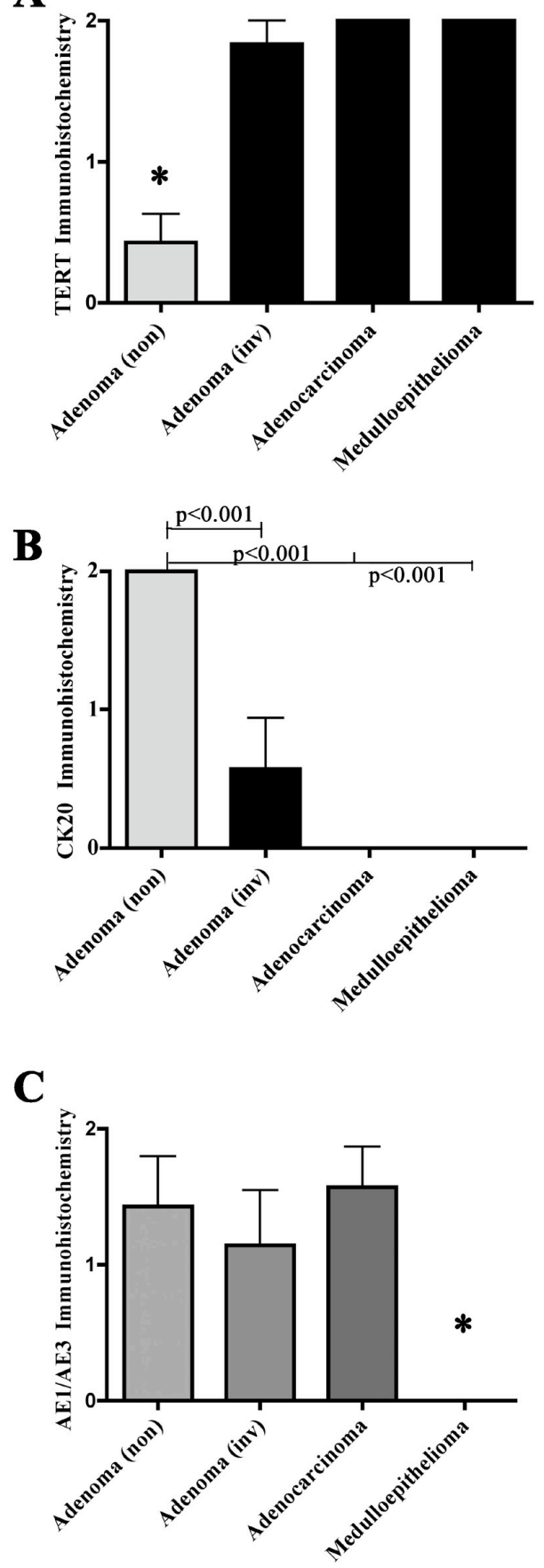